REVIEW

\title{
Acute coronary syndromes: should women receive less antithrombotic medication than men?
}

\section{N Danchin}

\begin{abstract}
,
A recent meta-analysis of all randomised trials assessing the efficacy and safety of glycoprotein Ilb/llla agents with acute coronary syndromes showed that there was a significant interaction with sex. Explaining this difference requires an analysis of whether it has any pathophysiological basis, whether antithrombotic medications are indeed less efficacious in women in different clinical situations, and whether there are any specific reasons that may have led to the provocative results of the meta-analysis.
\end{abstract}

Correspondence to: Professeur N Danchin, Cardiologie, Hôpital Européen Georges Pompidou, 20 rue Leblanc, 75015 Paris, France; nicolas.danchin@ egp.ap-hop-paris.fr

Accepted 6 January 2003 n a meta-analysis of all randomised trials assessing the efficacy and safety of glycoprotein IIb/IIIa agents in 31042 patients with acute coronary syndromes, Boersma and colleagues $^{1}$ found that, although overall these agents appeared beneficial in the populations studied, there was a significant interaction with sex. Glycoprotein IIb/IIIa reduced the risk of death or myocardial infarction by $19 \%$ in men but increased it significantly by $15 \%$ in women. The question was therefore raised of the potential beneficial or harmful effects of the use of powerful antithrombotic medications in women with acute coronary syndromes, thereby questioning the validity of everyday practice in intensive care units. Answering this question requires an analysis of whether there is any pathophysiological basis why this would be the case, whether antithrombotic medications are indeed less efficacious in women in different clinical situations, and whether there are any specific reasons that may have led to the provocative results of the meta-analysis.

\section{DO PLATELETS AND THE HAEMOSTATIC SYSTEM REACT DIFFERENTLY IN MEN AND IN WOMEN?}

There is no conclusive evidence that, in acute situations, the haemostatic system of women would be less likely to benefit from antithrombotic medications. If anything, most reports suggest increased platelet reactivity in women, with a greater sensitivity of the platelets of women to aggregating stimuli, which may provide a rationale for the use of potent antithrombotic medications in women. ${ }^{2-6}$ It has also been shown that the platelets of premenopausal women, when submitted to aggregating stimuli, convert a greater proportion of available glycoprotein IIb/IIIa receptors to an activated state than do the platelets of men $(50-80 \%$
Heart 2004;90:363-366. doi: 10.1136/hrt.2002.003483

increase compared with men). ${ }^{7}$ Other coagulation factors such as factor VII may also react differently in men and in women. ${ }^{8}$

\section{ARE ANTITHROMBOTIC MEDICATIONS LESS EFFICACIOUS IN WOMEN?}

In acute ST elevation myocardial infarction, the Fibrinolytic Therapy Trialists' collaborative group meta-analysis of 58600 patients in randomised trials of thrombolysis versus placebo showed that mortality was lower for both women and men treated with intravenous thrombolysis. ${ }^{9}$ In addition, the efficacy of thrombolytic agents for reopening the culprit artery was found to be similar in the GUSTO I (global utilization of streptokinase and t-PA for occluded coronary arteries I) angiographic substudy. At 90 minutes, $33.5 \%$ of men and $30.9 \%$ of women had an occluded culprit artery (TIMI (thrombolysis in myocardial infarction) grade 0 or 1 ), and $37.8 \%$ and $38.5 \%$, respectively, had a fully patent artery (TIMI grade 3 ). Reocclusion rates were not significantly different in women $(8.7 \%)$ and in men $(5.1 \%) .^{10}$ Likewise, in the TIMI $11 \mathrm{~A}$ trial assessing the efficacy of the low molecular weight heparin enoxaparin, administered for non-ST segment elevation acute coronary syndromes, sex did not influence the anti-Xa activity recorded after enoxaparin administration. ${ }^{11}$

Things may look a bit different regarding antiplatelet agents. In the HOPE (heart outcomes prevention evaluation) trial of patients with known coronary artery disease or diabetes

Abbreviations: CREDO, clopidogrel for the reduction of events during observation; CURE, clopidogrel in unstable angina to prevent recurrent events; EPIC, evaluation of c7E3 Fab in the prevention of ischemic complications; EPILOG, evaluation of PTCA to improve long-term outcome with abciximab GP Ilb/Illa blockade; EPISTENT, evaluation of platelet $\mathrm{llb} / \mathrm{lll}$ a inhibitor for stenting; ESPRIT, enhanced suppression of the platelet GP Illb/llla receptor with Integrilin therapy; FRISC II, Fragmin and fast revascularization during instability in coronary artery disease; GUSTO, global utilization of streptokinase and t-PA for occluded coronary arteries I; GUSTO IV ACS, global utilization of strategies to open occluded arteries IV, acute coronary syndromes; HOPE, heart outcomes prevention evaluation; PARAGON, platelet Ilb/Illa antagonism for the reduction of acute coronary syndrome events in a global organization network; PRISM, platelet receptor inhibition for ischemic syndrome management; PRISM-PLUS, platelet receptor inhibition in ischemic syndrome management in patients limited by unstable signs and symptoms; PURSUIT, platelet glycoprotein Ilb/ Illa in unstable angina: receptor suppression using Integrilin therapy; TIMI, thrombolysis in myocardial infarction; WISE, women's ischemia syndrome evaluation 
mellitus (that is, a clinically stable population), female sex was an independent predictor of the urinary concentration of thromboxane B2, a marker of aspirin resistance, which in turn was a predictor of subsequent cardiovascular events in aspirin treated patients. ${ }^{12}$ In the CURE (clopidogrel in unstable angina to prevent recurrent events) trial, which included patients with acute coronary syndromes randomly assigned to clopidogrel or placebo in addition to their usual management, there was no significant interaction between sex and clopidogrel efficacy. However, the benefit on cardiovascular death and myocardial infarction or stroke prevention for clopidogrel treated patients was less pronounced in women than in men. ${ }^{13}$ Conversely, in the CREDO (clopidogrel for the reduction of events during observation) trial, a test of the efficacy of clopidogrel in addition to aspirin in patients undergoing elective percutaneous coronary interventions, the reduction in the primary end point (death, myocardial infarction, or stroke at one year) tended to be greater in women $(32.1 \%)$ than in men $(24.5 \%) .{ }^{14}$

With glycoprotein IIb/IIIa receptor antagonists, there was no reported influence of sex on the antiplatelet activity of eptifibatide in the platelet glycoprotein IIb/IIIa in unstable angina: receptor suppression using integrilin therapy (PURSUIT) trial (a population with non-ST segment elevation acute coronary syndromes). ${ }^{15}$ In all trials of glycoprotein IIb/IIIa blockers in the setting of percutaneous coronary interventions, the benefit appears to be virtually identical in men and in women. In a meta-analysis of the abciximab trials (EPIC (evaluation of C7E3 Fab in the prevention of ischemic complications), EPILOG (evaluation of PTCA to improve long-term outcome with abciximab GP IIb/IIIa blockade), and EPISTENT (evaluation of platelet IIb/IIIa inhibitor for stenting)), which enrolled 4824 men and 1771 women undergoing percutaneous coronary interventions in various clinical settings including acute coronary syndromes, the percentage of death, myocardial infarction, or urgent revascularisation by 30 days was reduced from $11.3 \%$ to $5.8 \%$ in men compared with $12.7 \%$ to $6.5 \%$ in women. ${ }^{16}$ Similar observations were made with eptifibatide in the ESPRIT (enhanced suppression of the platelet GP IIb/IIIa receptor with Integrilin therapy) trial, in which 2064 patients underwent elective percutaneous coronary interventions and were treated with aspirin and a thienopyridine. ${ }^{17}$ In the whole study population, at 48 hours the composite of death, myocardial infarction, urgent target vessel revascularisation, or unplanned glycoprotein IIb/IIIa use was observed in 10.5\% of women and $7.9 \%$ of men $(p=0.08)$, suggesting a higher risk for percutaneous coronary interventions in women. At 48 hours, eptifibatide reduced the risk of death, infarction, and target vessel revascularisation from $14.5 \%$ to $6.0 \%$ in women versus $9.0 \%$ to $6.8 \%$ in men. At one year, these differences persisted: $28.9 \% \vee 20.0 \%$ for women and $19.5 \% \vee 16.6 \%$ for men. There was no statistical interaction between treatment and sex at either 48 hours $(p=0.063)$ or one year $(\mathrm{p}=0.2)$. In addition, recent observational data in a series of 1215 patients undergoing percutaneous intervention (32\% with unstable angina) showed that the one month outcome in terms of death, Q wave myocardial infarction, or target vessel revascularisation was similar in men $(3.27 \%)$ and women $(4.0 \%)$, suggesting that women derived more benefit from glycoprotein IIb/IIIa blockade than men (that is, glycoprotein IIb/IIIa inhibitors would be capable of "resetting" the risk for women at the same level as that for men). ${ }^{18}$

In contrast, the meta-analysis of all six randomised trials of glycoprotein IIb/IIIa blockers in patients with non-ST segment elevation acute coronary syndromes for whom revascularisation was not specifically recommended (PRISM (platelet receptor inhibition for ischemic syndrome management), PRISM-PLUS (platelet receptor inhibition in ischemic syndrome management in patients limited by unstable signs and symptoms), PARAGON A (platelet IIb/IIIa antagonism for the reduction of acute coronary syndrome events in a global organization network), PARAGON B, PURSUIT, and GUSTO IV ACS (global utilization of strategies to open occluded arteries IV, acute coronary syndromes)) showed a clearly detrimental effect of glycoprotein IIb/IIIa blockade on the occurrence of death or myocardial infarction by 30 days in women. This was significantly increased by $15 \%$ compared with a reduction by $19 \%$ in men. ${ }^{1}$ Although there were important differences in baseline characteristics in men and women (women were older and more often diabetic but men more often had a previous myocardial infarction or previous myocardial revascularisation, as well as increased creatine kinase MB fraction concentrations on admission), the interaction between treatment efficacy and sex persisted after multivariate adjustment.

\section{REASONS FOR THE DISCREPANCY BETWEEN THE META-ANALYSIS IN ACUTE CORONARY SYNDROMES AND OTHER STUDIES: THE IMPORTANCE OF POPULATION SELECTION}

At this stage, one may conclude that glycoprotein IIb/IIIa inhibitors (and, more generally, antithrombotic medications) are at least as efficacious in women as in men in a number of clinical settings but that they had no efficacy whatsoever in the populations in the trials of acute coronary syndromes. The most likely explanation for this finding may be that the women in the trials of acute coronary syndromes were not an appropriate target for using powerful antithrombotic agents. Indeed, there is no question that women included in the percutaneous coronary intervention trials or those in the ST elevation myocardial infarction trials had definite coronary artery disease. In these clearly characterised clinical settings, antithrombotic medications appear as efficacious in women as in men. In contrast, there is a vast amount of evidence that a fair proportion of the women taking part in the studies with suspected non-ST segment elevation acute coronary syndromes have no coronary artery disease (or at least normal coronary angiograms). In the women's ischemia syndrome evaluation (WISE) study, reflecting "real world" practice in the USA, data from the coronary angiographic analysis for 323 women with suspected ischaemic chest pain referred for coronary angiography showed that $34 \%$ had no coronary artery disease and $23 \%$ had minimal disease. Only $43 \%$ had at least one coronary artery stenosis $>50 \% .{ }^{19}$ Similarly, in the Scandinavian FRISC II (Fragmin and fast revascularization during instability in coronary artery disease) trial of patients with non-ST segment elevation acute coronary syndromes (749 women, 1708 men), objective markers of the presence of coronary artery disease were less often present in women: pathological Q waves on the ECG, $14 \%$ v 20\% ( $p=0.001)$; and troponin $\mathrm{T}$ increase, $47 \% \vee 62 \%(\mathrm{p}<0.001) .{ }^{20}$ As the FRISC II trial was designed to compare an invasive versus a non-invasive strategy, virtually all patients in the invasive arm underwent coronary angiography, therefore avoiding any problem of selection bias in referral to angiography. In this arm of the trial, $25 \%$ of women, compared with $9.5 \%$ of men, had no significant coronary artery disease. In the PURSUIT trial, 5567 patients underwent coronary angiography during the index hospitalisation. Of those, $12 \%$ had no significant coronary artery disease. Female sex was one of the main independent predictors of the absence of significant coronary artery disease (relative risk (RR) 2.51, 95\% confidence interval (CI) 2.02 to 3.03). ${ }^{21}$ Though acute coronary syndromes are usually caused by plaque rupture and may occur at the site of plaques that are only mild on coronary angiography, there is no specific documentation that plaque rupture occurs more often on mild plaques in 
women than in men. Finally, in the meta-analysis from Boersma and colleagues, ${ }^{1}$ significantly more men than women had increased troponin concentrations or underwent myocardial revascularisation by either percutaneous or surgical interventions $(49 \% \vee 37 \%$, and $42 \% \quad v 31 \%$, respectively), both probably being correlated with the presence of authentic coronary artery disease. Of note in the meta-analysis, in the population with known concentrations of troponins on admission (7002 men and 4057 women), the sex difference in treatment effect disappeared if troponin status was added to the multivariate model. In patients with increased troponin concentrations on admission, glycoprotein IIb/IIIa treatment was associated with improved outcomes for both men and women (fig 1). Interestingly, in the PURSUIT trial eptifibatide treatment was beneficial only for patients with significant coronary artery disease. ${ }^{21}$ Along the same lines, in the population of the PURSUIT trial from the USA, in which twice as many patients underwent myocardial revascularisation as in the other participating countries, the efficacy of eptifibatide was equivalent in men and women..$^{22}$ Therefore, considering both the ECG and biochemical markers, as well as the coronary angiographic data, it seems highly plausible that a much higher proportion of the women than of the men in these acute coronary syndromes trials did not have true coronary artery disease. Given this possibility, it is no longer surprising that, for the whole population of women, the beneficial effect of the medications would have been obliterated by a lack of efficacy in those without coronary artery disease, who did not really need them and in whom they might have increased the bleeding risk.

\section{SAFETY ISSUES}

Indeed, the safety of the use of powerful antithrombotic medications is also part of the story, as the beneficial effect of the drugs in terms of efficacy may be counterbalanced by an increased risk of bleeding. In the abciximab trials during percutaneous interventions, major bleeding events occurred in $2.9 \% v 3.0 \%$ of women (not significant) and $2.7 \% v 1.3 \%$ of men $(p<0.01)$ treated with placebo versus abciximab,

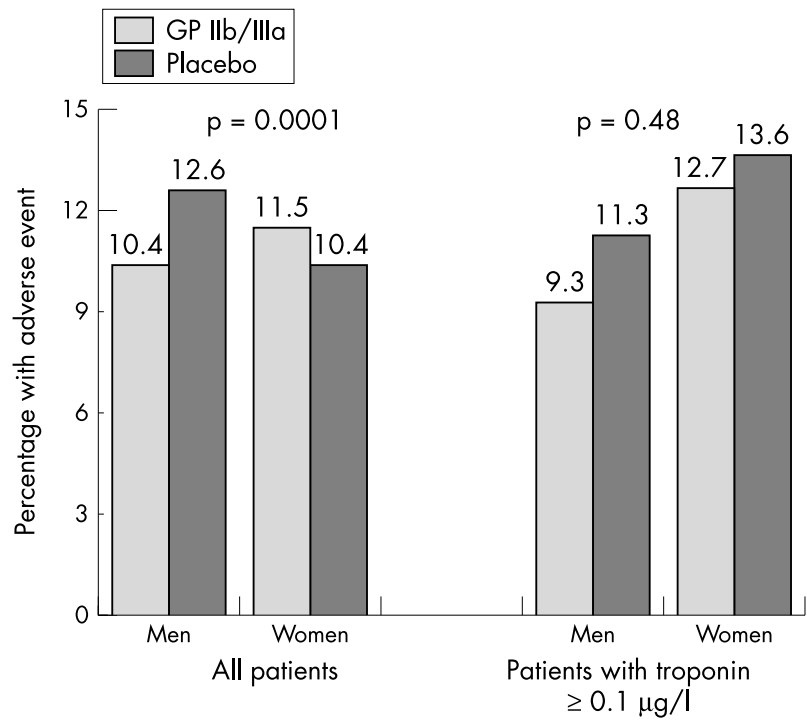

Figure 1 Effects of glycoprotein (GP) Ilb/llla blockade in the metaanalysis of trials in patients with acute coronary syndromes. 'The evidence of heterogeneity according to the sex of the patients in the whole population (left) is no longer present if the population is restricted to patients with increased troponin concentrations on admission (right). respectively. Minor bleeding occurred more often in women receiving abciximab $(6.7 \% \vee 4.7 \%)$, whereas there was no difference in men $(2.2 \% v 2.3 \%) .{ }^{16}$ The difference was more notable in the patients who received high dose heparin at the time of the procedure. Age, however, appeared to be the most important determinant of the risk of bleeding. Likewise, in the ESPRIT trial, major and minor bleeding was more common in women who received eptifibatide $(2.4 \% v 0.8 \%$ and $5.5 \% \vee 2.4 \%$, respectively), whereas the difference was much less in men $(1.0 \% \quad v \quad 0.3 \%$ and $2.1 \% \quad v \quad 1.8 \%$, respectively). ${ }^{17}$ The difference between men and women, however, was no longer significant in multivariate models including age and weight. Nearly two thirds $(64 \%)$ of the bleeding complications in women occurred at the femoral access site, compared with $36 \%$ in men. In the meta-analysis from Boersma and colleagues, ${ }^{1}$ the increased risk of major bleeding was slightly higher in women (RR 2.2, 95\% CI 1.6 to 2.9 ) than in men (RR $1.6,95 \%$ CI 1.3 to 2.0 ) but there was no evidence of heterogeneity according to sex. To summarise, there is no consistent evidence that the increase in bleeding risk after glycoprotein IIb/IIIa blockade is much higher in women than in men and that it would be likely to offset the benefits of these agents in terms of efficacy.

\section{CONCLUSION}

From all these data, it appears that glycoprotein IIb/IIIa receptor blockers, as well as other antithrombotic medications, are likely to benefit women as much as men, provided they are targeted at the right population, namely patients with significant coronary artery disease at high risk of developing clinical complications. In such a population with acute coronary syndromes, which can be stratified by clinical, electrocardiographic, and biochemical data recorded on and within the first hours of admission, there is a large amount of evidence that the combination of the use of glycoprotein IIb/ IIIa inhibitors and an invasive strategy with early angiography and myocardial revascularisation, such as recently recommended by the European Society of Cardiology, is beneficial, for both women and men. ${ }^{23}$ The meta-analysis from Boersma and colleagues, ${ }^{1}$ when read in the light of the other information available, does not contradict this statement.

\section{REFERENCES}

1 Boersma E, Harrington RA, Moliterno DJ, et al. Platelet glycoprotein Ilb/Illa inhibitors in acute coronary syndromes: a meta-analysis of all major randomised clinical trials. Lancet 2002;359:189-98.

2 Johnson M, Ramey E, Ramwell PW. Sex and age differences in human platelet aggregation. Nature 1975;253:355-7.

3 Reading HW, Rosie R. Age and sex differences related to platelet aggregation. Biochem Soc Transcr 1980;8:180-1.

4 Michimata T, Imamura M, Mizuma H, et al. Sex and age differences in soluble guanylate cyclase activity in human platelets. Life Sci 1996;58:415-9.

5 Agarwal KC. Modulation of vasopressin actions on human platelets by plasma adenosine and theophylline: gender differences. J Cardiovasc Pharmacol 1993;21:1012-8.

6 Markham SM, Dubin NH, Rock JA. The effect of the menstrual cycle and of decompression stress on arachidonic acid-induced platelet aggregation and on intrinsic platelet thromboxane production in women compared with men. Am J Obstet Gynecol 1991;6:1821-9.

7 Faraday N, Goldschmidt-Clermont PJ, Bray PF. Gender differences in platelet GP Ilb/Illa activation. Thromb Haemost 1997;77:748-54.

8 Danielsen R, Onundarson PT, Thors $\mathrm{H}$, et al. Activated and total coagulation factor VII and fibrinogen in coronary artery disease. Scand Cardiol J 1998;32:87-95.

9 Fibrinolytic Therapy Trialists' Collaborative Group. Indications for fibrinolytic therapy in suspected acute myocardial infarction: collaborative overview of early mortality and major morbidity from all randomised trials of more than 1000 patients. Lancet 1994;343:311-22.

10 Woodfield SL, Lundergad CF, Reiner JS, et al. Gender and acute myocardial infarction: is there a different response to thrombolysis? J Am Coll Cardiol 1997;29:35-42.

11 Becker RC, Spencer FA, Gibson M, et al. Influence of patient characteristics and renal function on factor Xa inhibition pharmacokinetics and pharmacodynamics after enoxaparin administration in non-ST-segment elevation acute coronary syndromes. Am Heart J 2002;143:753-9. 
12 Eikelboom JW, Hirsh J, Weitz Jl, et al Aspirin-resistant thromboxane biosynthesis and the risk of myocardial infarction, stroke, or cardiovascular death in patients at high risk for cardiovascular events. Circulation 2002; 105: 1650-5.

13 Clopidogrel in Unstable Angina to Prevent Recurrent Events Trial Investigators. Effects of clopidogrel in addition to aspirin in patients with acute coronary syndromes without ST-segment elevation. N Engl J Med 2001;345:494-502.

14 Steinbuhl SR, Berger PB, Mann JT III, for the CREDO Investigators, et al. Early and sustained dual oral antiplatelet therapy following percutaneous coronary intervention: a randomized controlled trial. JAMA 2002; 288:2411-20

15 Tardiff BE, Jennings LK, Harrington RA, for the PERIGEE Investigators, et al. Pharmacodynamcs and pharmacokinetics of eptifibatide in patients with acute coronary syndromes: prospective analysis from PURSUIT. Circulation 2001; 104:405

16 Cho L, Topol EJ, Balog C, et al. Clinical benefit of glycoprotein Ilb/Illa blockade with abciximab is independent of gender: pooled analysis of EPIC, EPILOG and EPISTENT trials. J Am Coll Cardiol 2000;36:381-6.

17 Fernandes LS, Tcheng JE, O'Shea JC, for the ESPRIT Investigators, et al. Is glycoprotein Ilb/Illa antagonism as effective in women as in men following percutaneous coronary intervention? Lessons from the ESPRIT study. J Am Coll Cardiol 2002;40:1085-91
18 lakovou I, Dangas G, Mehran R, et al. Gender differences after coronary artery stenting with use of glycoprotein Illb/lla inhibitors. Am J Cardiol 2002;89:976-9.

19 Sharaf BL, Pepine CJ, Kerensky RA, et al. Detailed angiographic analysis of women with suspected ischemic chest pain (pilot-phase data from the NHLBIsponsored women's ischemia syndrome evaluation [WISE] study angiographic core laboratory). Am J Cardiol $2001 ; 87: 937-41$.

20 Lagerqvist B, Säfström K, Stähle E, and the FRISC II Study Group Investigators, et al. Is early invasive treatment of unstable coronary artery disease equally effective for both women and men? J Am Coll Cardiol 2001;38:41-8.

21 Roe MT, Harrington RA, Prosper DM, for the PURSUIT Trial Investigators, et al. Clinical and therapeutic profile of patients presenting with acute coronary syndromes who do not have significant coronary artery disease. Circulation 2000:102:1101-6.

22 Lincoff AM, Harrington RA, Califf RM, et al. Management of patients with acute coronary syndromes in the United States by platelet glycoprotein Illb/llla inhibition. Insights from the platelet glycoprotein Ilb/Illa in unstable angina: receptor suppression using integrilin therapy (PURSUIT) trial. Circulation 2000:102:1093-100.

23 Bertrand ME, Simoons ML, Fox KAA, et al. Management of acute coronary syndromes in patients presenting without persistent ST-segment elevation. The task force on the management of acute coronary syndromes of the European Society of Cardiology. Eur Heart J 2002;23:1809-40.

\section{IMAGES IN CARDIOLOGY}

\section{Sinus of Valsalva to right atrial fistula}

7 r he patient is a 46 year old man with hypertension who on routine physical exam was noted to have a continuous cardiac murmur. Transthoracic echocardiogram demonstrated a sinus of Valsalva fistula extending into the right atrium. A transoesophageal echocardiogram (TOE) was then performed to better characterise the abnormality (see panels). The patient underwent closure of the aorto-right atrial fistula with a pericardial patch. The patient had an uneventful postoperative course and was discharged home. Aortic cusp fistulas should be part of the differential diagnosis when a continuous cardiac murmur is auscultated.

M S Chen, H Gurm, C R Asher asherc@ccf.org

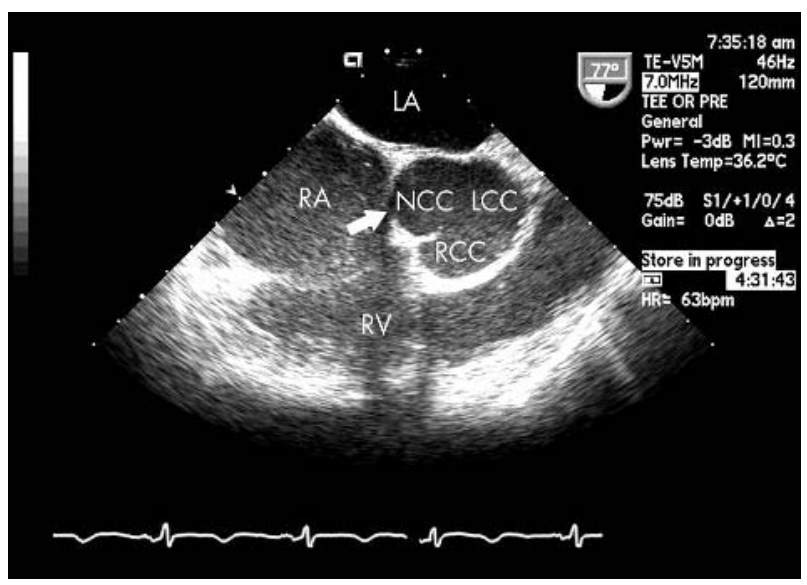

TOE short axis view at the level of the aortic valve. A defect (arrowhead) is visualised between the non-coronary cusp and the right atrium. LCC, left coronary cusp; NCC, non-coronary cusp; RA, right atrium; RCC, right coronary cusp; RV, right ventricle.

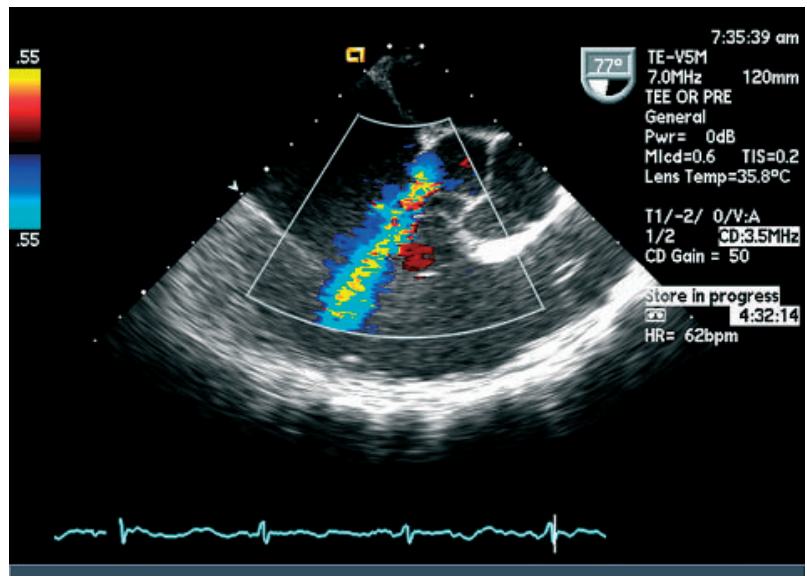

Colour Doppler of TOE short axis view at the level of the aortic valve. Blood flow can be seen passing from the non-coronary cusp into the right atrium.

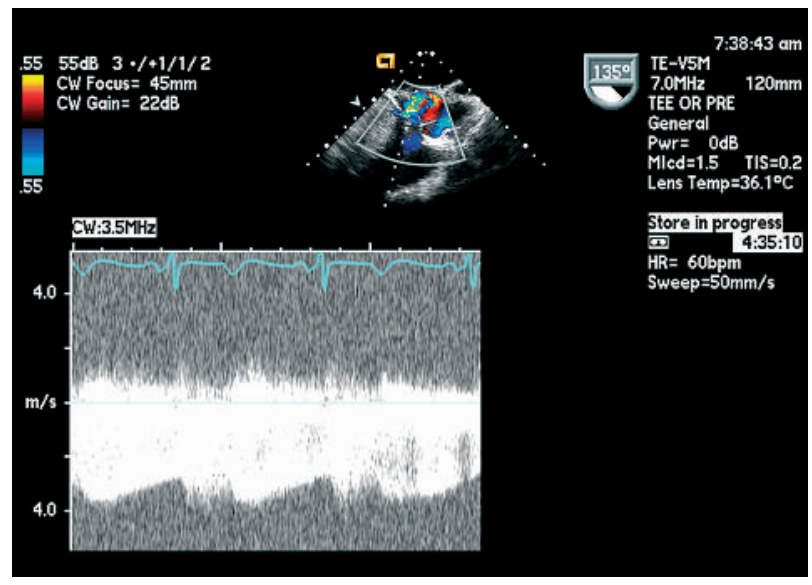

Continuous wave Doppler of TOE short axis view at the level of the aortic valve. A high velocity flow through the fistula is evident in both systole and diastole. 